\title{
Constrictors, Injurious Wildlife Listings, and the Reptile Industry ${ }^{1}$
}

Ariel H. Collis and Robert N. Fenili

Georgetown Economic Services, LLC, Washington, D.C.

$\mathrm{I}_{\mathrm{p}}^{\mathrm{n}}$ n 2006, the South Florida Water Management District petitioned the U.S. Fish and Wildlife Service ("Service") for federal assistance in controlling the population of Burmese Pythons (Python bivittatus ${ }^{2}$ ) in Florida ${ }^{3}$. In response, the Service and the National Park Service requested that the U.S. Geological Service conduct a risk assessment of nine constrictor snake species ("nine snakes"). In 2009, the USGS reported
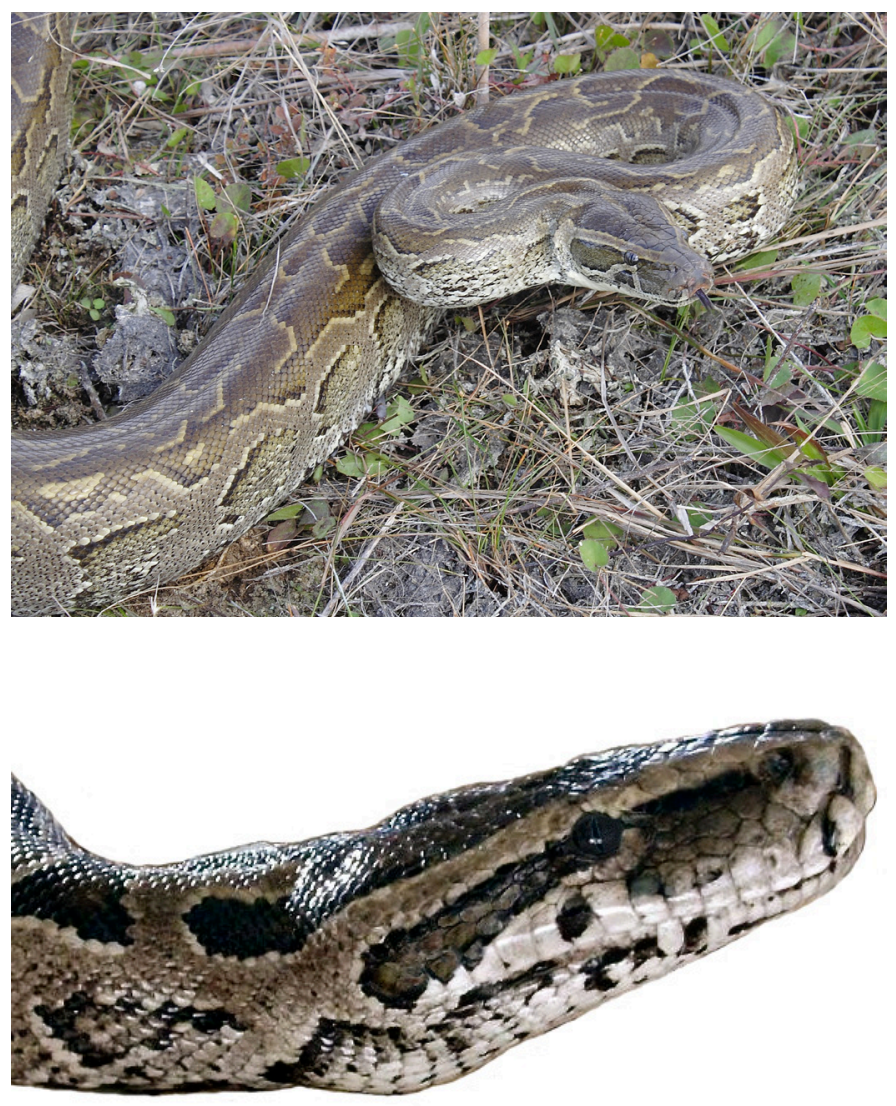

Both the Northern (Python sebae, top) and Southern African Rock Pythons (P. natalensis, bottom) are included in the four species listed on 17 January 2012 as injurious wildlife. Photographs by L. Oberhofer (National Park Service) and L. Kroone. that the overall organism risk potential ranged from medium (Reticulated Python, Green Anaconda, DeSchauensee's Anaconda, and Beni Anaconda ${ }^{4}$ ) to high (Burmese Python, Northern African Python, Southern African Python, Boa Constrictor, and Yellow Anaconda $\left.{ }^{5}\right) .{ }^{6}$ In 2010, the Service proposed a rule to list the nine snakes as injurious wildlife under the Lacey Act. ${ }^{7}$ Species listed as injurious wildlife by the Service cannot be imported or transported between states lines. They can be exported but only if the owner lives within a state with a designated port and only after the owner acquires the appropriate permits from the Service. ${ }^{8}$ When the Service proposed the rule to list the nine snakes as injurious wildlife, the Brown Tree Snake (Boiga irregularis) was the only reptile on the list.

In response to the proposed rule, reptile industry participants claimed that the nine-snake listing would result in a

\footnotetext{
${ }^{1}$ Opinions expressed in commentaries do not necessarily reflect those of the IRCF or the editors of Reptiles \& Amphibians.

${ }^{2}$ Some authorities continue to recognize the Burmese Python as a subspecies of the Indian Python (i.e., Python molurus bivittatus).

${ }^{3}$ See: Letter from Kevin McCarty, Governing Board Chairman of the South Florida Water Management District, to H. Dale Hall, Director of the U.S. Fish and Wildlife Service, 23 June 2006.

${ }^{4}$ Python reticulatus, Eunectes murinus, E. deschauenseei, and E. beniensis, respectively.

${ }^{5}$ Python bivittatus, P. sebae, P. natalensis, Boa constrictor, and Eunectes notaeus, respectively.

${ }^{6}$ The organism risk potential is a measure of the probability that these snakes will breed, spread, and do environmental damage. R.N. Reed and G.H. Rodda. 2009. Giant Constrictors: Biological and Management Profiles and an Establishment Risk Assessment for Nine Large Species of Pythons, Anacondas, and the Boa Constrictor. U.S. Geological Survey, Reston, Virginia, p. 7.

7 The Lacey Act, enacted into law in 1900, prohibits the purchase, transport, and trade of wildlife taken in violation of any law of the United States or any foreign country. The Act also prohibits the import and interstate transport of any species determined by the Service to be ecologically harmful. Listing reptiles as injurious wildlife is unusual.

${ }^{8}$ Specifically, the Service stated that: "If the proposed rule is made final, live snakes, gametes, or hybrids of the nine species or their viable eggs could be imported only by permit for scientific, medical, educational, or zoological purposes, or without a permit by Federal agencies solely for their own use. The proposed rule, if made final, would also prohibit any interstate transportation of live snakes, gametes, viable eggs, or hybrids of the nine species currently held in the United States." 75
} FR 11808, 12 March 2010. 
significant negative economic impact on the reptile industry. ${ }^{9}$ In this paper, we address the economic impact of the Service's proposal to list nine snakes as injurious wildlife. We also estimate the impact of a compromise rule to list only four of the nine snakes as injurious wildlife.

\section{Overview of the U.S. Reptile Industry}

Despite the fact that nearly five million U.S. households owned close to 14 million reptiles as pets, and reptile businesses earned revenues exceeding $\$ 1.0$ billion from the sale, care, and housing of reptiles, the reptile industry has been studied little ${ }^{10}$. As a consequence, the imposition of federal rules and regulations that directly affect this industry, such as the Lacey Act rule change, have been made without the information necessary to assess the economic impacts of these rules on the participants that comprise the U.S. reptile industry. We were commissioned by the U.S. Association of Reptile Keepers to provide a profile of the industry. Based on

Table 1. Revenues of the U.S. reptile industry in 2009 by type of business.

\begin{tabular}{lcc} 
Business Type & Estimated Revenues (Million \$) \\
Lower Bound & Upper Bound \\
\hline Breeders & 141.7 & 183.2 \\
\hline Importers/Exporters & 28.0 & 30.0 \\
\hline Wholesalers & 17.0 & 22.0 \\
\hline Retailers & 277.6 & 363.8 \\
\hline Manufacturers & 56.5 & 70.5 \\
\hline Food Breeders & 22.0 & 25.5 \\
\hline Medical Costs & 419.5 & 713.2 \\
\hline Reptile Show Promoters & 10.0 & 20.0 \\
\hline Delivery Services & 5.0 & 7.0 \\
\hline Total & $\mathbf{9 7 7 . 3}$ & $\mathbf{1 , 4 3 5 . 2}$ \\
\hline
\end{tabular}

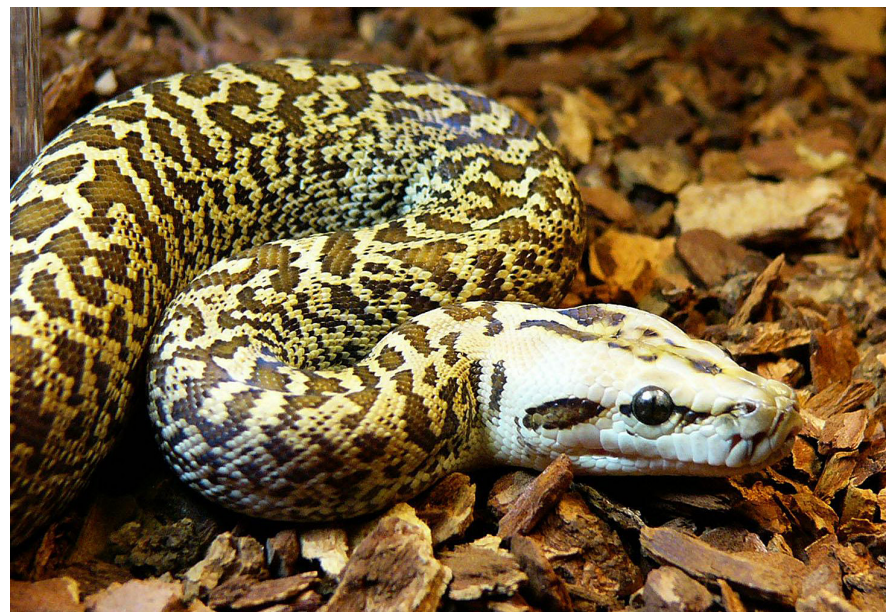

a survey of industry members, publicly available information, and conversations with various reptile businesses and breeders, we estimate that reptile businesses collectively generated revenues of $\$ 1-1.4$ billion in 2009. Table 1 provides lowerand upper-bound estimates of revenues realized in 2009 by various types of reptile businesses in the United States. Table 1 also shows that medical costs account for the largest share of reptile industry revenues and that retailers (including internet retailers) account for the second largest share.

\section{Listing Nine Snakes}

Based on our review of the industry, we estimate that a limitation on sales of the nine snakes - the intended effect of such an injurious wildlife listing - would result in lower industry revenues on the order of \$76-104 million per year. Reptile businesses with a higher proportion of their sales involving the nine snakes will bear the brunt of the lower revenues. These revenue losses would continue into the indefinite future. Ten years after enactment of the rule, present discounted revenue losses are estimated to run between $\$ 500$ million and $\$ 1.2$ billion, assuming historical industry sales growth.

Imports.-If listed, all imports of the nine constrictor species would be banned. Therefore, current and future revenues realized from importing any of the named species would be eliminated. However, the import ban does not affect only importers. Imported reptiles make their way through many stages of the U.S. reptile distribution chain. Revenues realized by the sale of these snakes at each stage of the distribution chain would also be eliminated. ${ }^{11}$

\footnotetext{
${ }^{9}$ The industry also contended that the rule would not attain its intended effect, namely to limit the growth and spread of feral populations of the nine snakes.

${ }^{10}$ See: 2009/2010 American Pet Products Association, National Pet Owners Survey.

${ }^{11}$ For example, banning a Boa Constrictor prevents the sales of that constrictor from (a) an importer to a distributor, (b) a distributor to a pet store, and (c) a pet store to a pet owner.
}

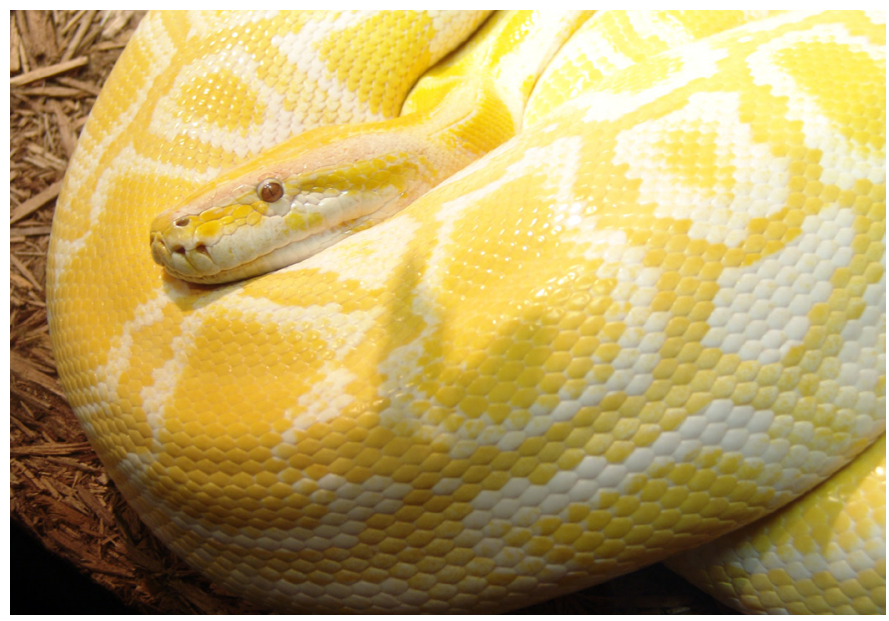

The cost of captive-bred constrictor pattern morphs, such as these "granite" and amelanistic Burmese Pythons (Python bivittatus), dropped precipitously after the U.S. Fish and Wildlife Service announced that they were considering a rule to list nine large constrictors as injurious wildlife. 
Exports.-Unlike imports, the proposed rule does not explicitly eliminate exports of the named species. However, federal law states that all reptiles must be exported from one of 18 designated ports. ${ }^{12}$ Therefore, any business or individual located in a state without a port within its boundaries would be excluded from exporting any of the nine snakes because the Lacey Act would make it a federal offense for anyone to transport a listed species across state lines. ${ }^{13}$

Price Effects.-Major reptile business owners report that prices for each of the nine snakes have already decreased significantly in anticipation of the Service's proposal. Our estimates of the impact of the ban do not include the reduction in the price of snakes that occurred almost immediately after the Service's announcement that they were considering a rule to list the nine snakes as injurious wildlife. As expected, the largest price reductions have been for designer snakes, which are more commonly referred to as morphs. Morphs are a trade name for reptiles that are bred to have unique color patterns and body types. One dealer reported that prices for some Boa Constrictor morphs have decreased from $\$ 1,000$ to $\$ 30$. In addition, many breeders (and those thinking of becoming breeders) of the nine snakes have been unwilling to invest in "good" parents (those that exhibit the desired genetic traits) over the past few years because of concern that they will be limited to intrastate sales of the offspring. In short, buyers of these snakes believe that without access to customers across the country, they would not be able to earn an adequate return on their investment to justify their snake purchase. Given that breeders, pet owners, and retailers are increasingly conducting business at reptile shows and over the internet, and given that many breeders increasingly depend on interstate sales generated by the internet and out-of-state reptile shows, if the proposed regulation passes, businesses operating within the confines of the Lacey Act are unlikely to have access to the critical number of customers needed to continue operations.

\footnotetext{
12 These ports are located in Anchorage, Atlanta, Baltimore, Boston, Chicago, Dallas/Ft. Worth, Houston, Honolulu, Los Angeles, Louisville, Memphis, Miami, New Orleans, New York, Newark, Portland, San Francisco, and Seattle. "Bringing Pets and Wildlife into the United States." U.S. Department of Customs and Border Protection, pp. 14-15.

${ }^{13}$ A review of the locations of exporters of the nine constrictor species in 2009 within LEMIS data shows that roughly $20 \%$ of exports, by number, were shipped to ports located outside of an exporter's home state. However, the $20 \%$ figure underestimates the effect of the ban on exports, since exporters often purchase reptiles from other breeders and distributors. Some of the breeders and distributors from which exporters purchase snakes are located in states other than that of the exporter. Thus, if the ban were enacted, the exporter would be unable to acquire snakes from breeders and distributors located outside of his or her home state. We do not know the magnitude of these interstate transactions.
}

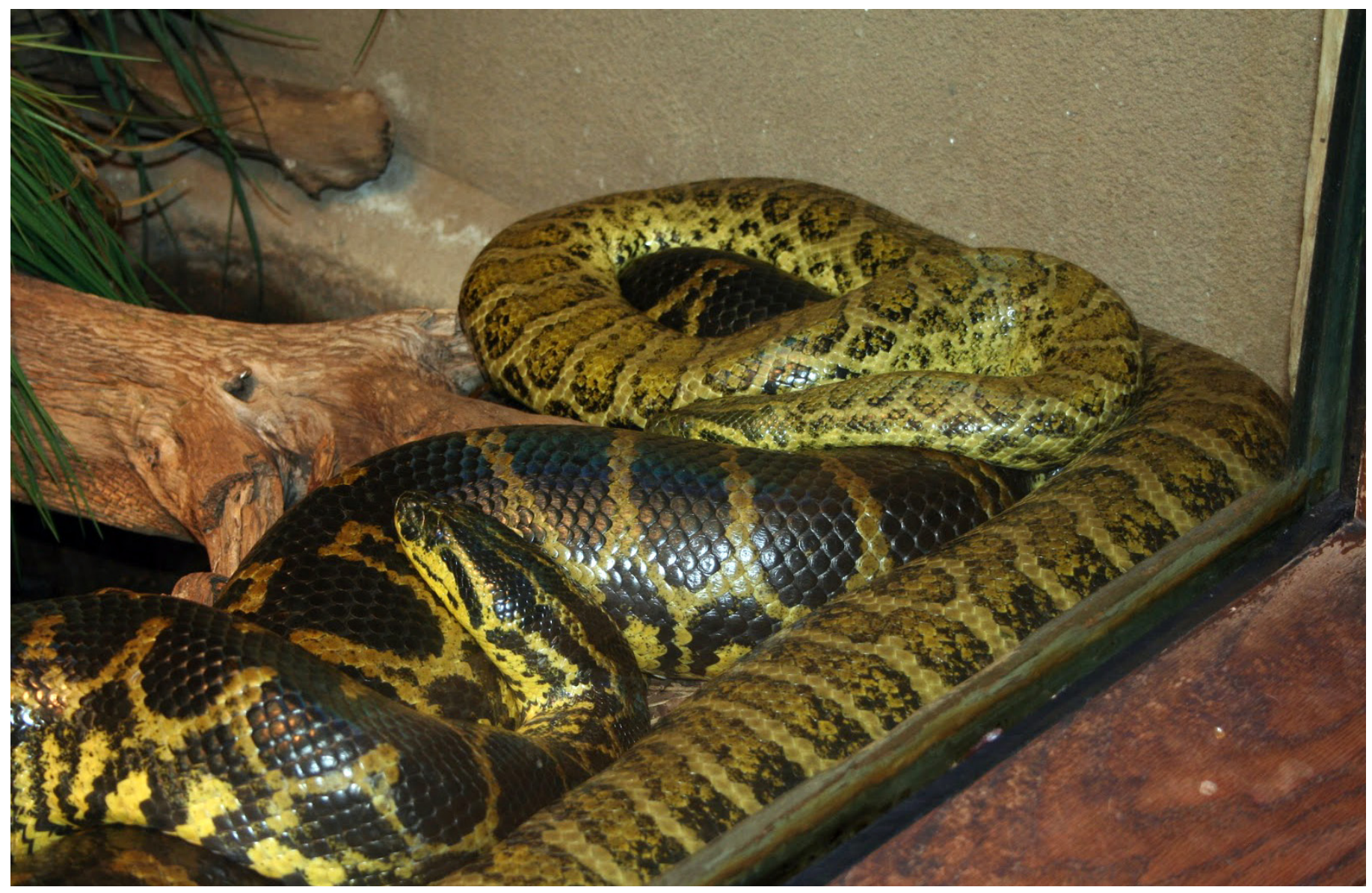

In 2009, the USGS reported that the overall organism risk potential was high for Yellow Anacondas (Eunectes notaeus). 
Holding Costs. - As with any pet or animal stock, snakes cost money to keep. These costs would continue if the listing goes into effect. However, once the likelihood of selling the snakes is eliminated or greatly diminished, the capital tied up in housing and feeding these snakes will no longer be available to make new purchases and expand operations. ${ }^{14}$ As a consequence, many breeding operations and stores would reduce purchases of new reptiles and equipment. The decrease in purchases would negatively impact other reptile breeders, wholesalers, and product manufacturers. An owner of a company that manufactures containers for snakes reported that fear of the potential constrictor ban has already started this cascade of impacts. He reported that due to the announcement of the proposed listing, Boa container sales have stagnated over the last year (i.e., 2010), leading to an increase in inventories and a decrease in cash flow, slowing the production of all new snake containers.

The magnitude of the economic costs incurred by listing the nine snakes as injurious wildlife depends in large part on the actions of current breeders. What is certain is that a listing of the snakes will result in: (1) The lost opportunity to make legal interstate sales; (2) the lost opportunity for some breeders to make foreign sales; and, (3) increased per-unit holding costs for keeping the snakes. Pet owners who possess but do not breed these nine snakes will also bear a significant burden from the listing. Owners that choose to keep rather than sell or dispose of their snakes will be limited in where they can move within the United States over the course of their pet snake's life, narrowing the range of their personal and career options.

We consider two scenarios with regard to the reaction of industry participants if the nine-snake listing were enacted. In a low-impact scenario, we posit that some breeders will continue to breed the listed constrictors, make intrastate sales, and make foreign sales. In a high-impact scenario, we posit that the combination of higher per-unit costs of breeding and maintaining the listed constrictors as well as the reduced market for the listed snakes, and the concomitant lower prices, will make it unprofitable to breed, keep, and sell these snakes. In this scenario, no revenues derived from these snakes or

Table 2. Estimates of economic impact of the nine-snake listing: First ten years (undiscounted).

$\begin{array}{ll}\text { No Growth } & 7 \% \text { Growth } \\ \text { (Million \$) } & \text { (Million \$) }\end{array}$

\begin{tabular}{lcc}
\hline High-Impact Scenario & & \\
\hline Lower Bound Estimate & 756.0 & $1,044.5$ \\
\hline Upper Bound Estimate & $1,036.0$ & $1,431.4$ \\
\hline Low-Impact Scenario & & \\
\hline Lower Bound Estimate & 428.1 & 591.5 \\
\hline Upper Bound Estimate & 692.8 & 811.0 \\
\hline
\end{tabular}

products and services for these snakes would be realized if the proposal were to be finalized. If the nine-snake rule were passed, the state of this industry is expected to fall somewhere between these scenarios.

Short-Term Economic Impact.-The collective industry loss in revenues in the first year after enactment of the rule, assuming the low-impact scenario, is $\$ 42.8-58.7$ million, and assuming the high-impact scenario, is \$75.6-103.6 million. Some have dismissed these estimates as "completely bogus." 15 However, in its economic analysis of the proposed rules, the Service estimated the nine-snake listings would result in a decline of sales of imports and domestic breed sales of the nine snakes of \$14.7-30.1 million per year. ${ }^{16}$ The Service also reported that "secondary" economic costs of a nine-snake listing would be in the range of \$42.0-86.2 million in the first year. The Service defined secondary costs as "how the annual decrease (due to a decrease in retail value) in the constrictor snake industry will affect economic output, job income, and local, state, and federal tax revenue ..."17 Whether one accepts our estimates or the Service's, the impact on the industry of a nine-snake listing is substantial.

Long-Term Economic Impact.-While the impact of a nine-snake listing in the first year alone is substantial, it is only a fraction of the revenue losses U.S. reptile businesses would experience over the longer term. Revenue losses over the first ten years after an enactment of the ban are significant, ranging from $\$ 591.5$ million to $\$ 1.4$ billion, based on a preenactment industry growth rate of $7 \%{ }^{18}$ (See Table 2 ).

The present discounted value of the lost revenue stream is between $\$ 505$ million and $\$ 1.2$ billion. Even assuming a zero-percent growth rate, lost industry revenues range from $\$ 428$ million to $\$ 1$ billion undiscounted, or from $\$ 372$ million to $\$ 901$ million, discounted. Under any of these scenarios, the long-term impact of a nine-snake listing is substantial. ${ }^{19}$ Among the nine snakes, the Boa Constrictor is by far the most economically important in terms of reptile industry

14 This raises another issue involving the dilemma reptile keepers would face with existing stocks of the snakes listed as injurious wildlife.

15 Morgan, C., "Bid to Curb Nationwide Snake Sales Stalls." The Miami Herald, 27 December 2011.

16 See: Rulemaking to List Four Constrictor Snake Species Under the Lacey Act: Indian Python (Python molurus), Northern African Python (Python sebae), Southern African Python (Python natalensis), and Yellow Anaconda (Eunectes notaeus), Final Economic Analysis, prepared by The U.S. Fish and Wildlife Service. 12 January 2012, p. 4.

${ }^{18} I d$ at 5.

${ }^{17}$ Exports associated with the nine snakes grew, on average, by $7 \%$ per year for the period 2008-2010 (LEMIS data). However, the general pricing trend among morphs is for prices to fall as breeders produce more of the existing morphs. Our opinion is that the expected lower-bound industry growth rate (assuming a zerosnake listing world) is $0 \%$, and the upper-bound growth rate is $7 \%$. The actual growth in such a world would fall between these two boundaries.

${ }^{19}$ Based on a $3.75 \%$ discount rate. This rate was the average bank prime rate for 2010. Federal Reserve Bank of St. Louis (http://rsearch.stlouisfed.org/fred2/categories/117) (accessed 11 April 2011). 

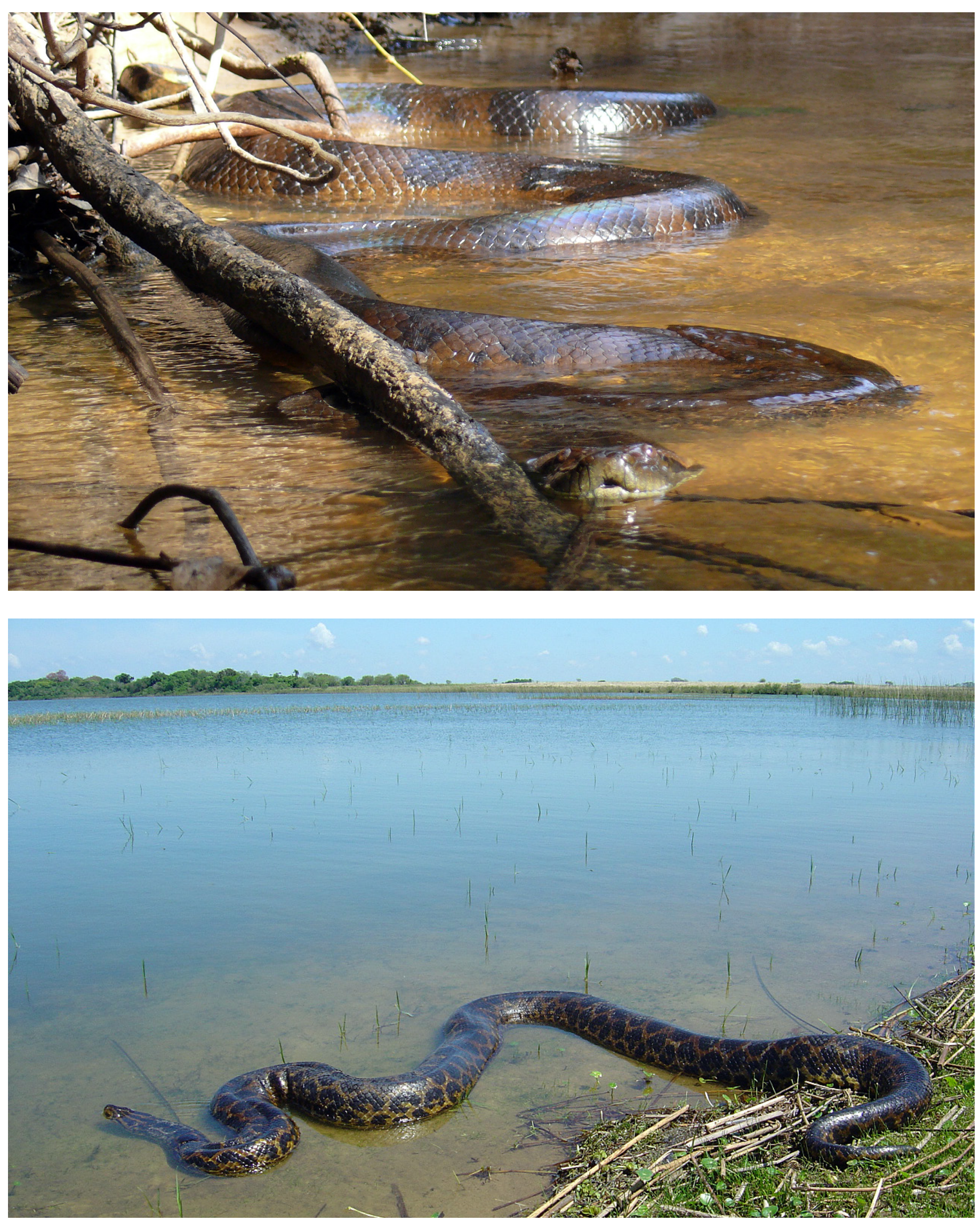

The Green Anaconda (Eunectes murinus, top) is not included on the short list of four species categorized as injurious wildlife by the USFWS, but the Yellow Anaconda (E. notaeus, bottom) is. Top photograph by Lutz Dirksen, bottom photograph by Tomas Waller. 
revenues. Boa morphs are the most popular, and are among the highest price morphs of the nine snakes. In addition, Boa Constrictors account for $70 \%$ of all imports and $70 \%$ of exports of these nine snakes.

Whether one agrees with our estimates of industry loss or with those of the Service, one fact is clear - since the Service's involvement, the uncertainty surrounding the legal status of the businesses in the reptile industry has had a major impact on current financial health of those businesses. The prices of many snakes have dropped, as buyers are hesitant to purchase a snake that may be listed as an injurious species. Because of this uncertainty, both the Service's and our estimates of the costs of regulations are underestimated given the fact that potential future regulations affect current prices and current decisions to breed, import, and buy snakes.

\section{Listing Four Snakes: A Compromise?}

On 17 January 2012, Ken Salazar, Secretary of the Department of the Interior, announced that the Service decided to list as injurious only four of the nine snakes; these are the Burmese Python, the Yellow Anaconda, and the Northern and Southern African Pythons. ${ }^{20}$ At a news conference, Salazar suggested that this four-snake listing was a compromise because it deals with the species that the Service considers the most immediate threat to the Everglades while "not suffocating commerce by overregulation." ${ }^{21}$ Each of the four listed snakes was deemed by the Service to have a high organism risk potential.

Of particular note, however, is the fact that the Boa Constrictor was not listed even though it was also deemed by the Service to have a high organism risk potential. Leaving the Boa Constrictor out of the listing considerably lessened the rule's impact on reptile industry participants, giving credence to the view expressed by Salazar that the U.S. government was attempting to find a balanced solution.

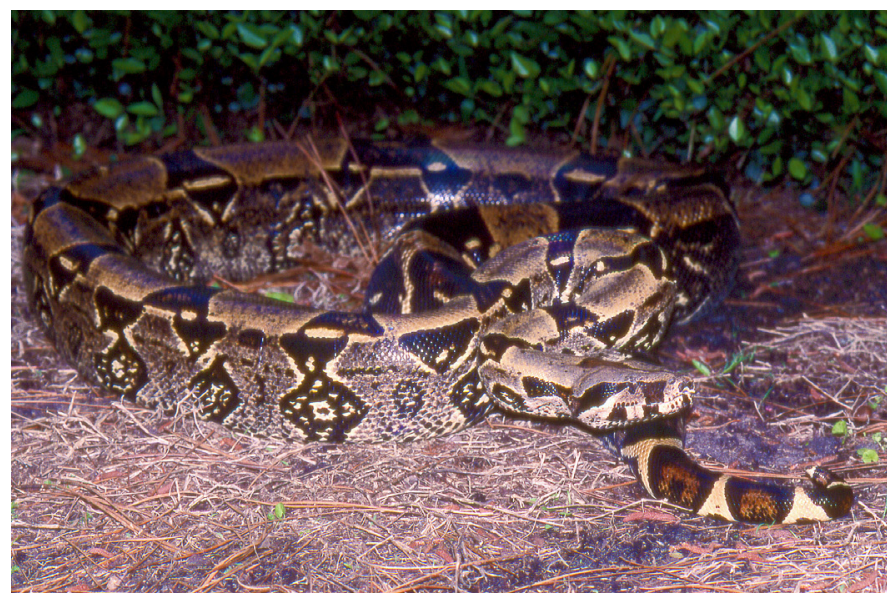

Boa Constrictors (Boa constrictor) were not listed as injurious wildlife in the 17 January 2012 announcement by the U.S. Fish and Wildlife Service. This is the principal difference between the economic costs of listing four versus nine species of large constrictors. Photograph by Kenneth L. Krysko.
Table 3. Estimates of economic impact of the four-snake listing: First ten years (undiscounted).

$\begin{array}{cc}\text { No Growth } & 7 \% \text { Growth } \\ \text { (Million \$) } & \text { (Million \$) }\end{array}$

\begin{tabular}{lcc}
\hline High-Impact Scenario & & \\
\hline Lower Bound Estimate & 151.2 & 208.9 \\
\hline Upper Bound Estimate & 207.2 & 286.3 \\
\hline Low-Impact Scenario & & \\
\hline Lower Bound Estimate & 85.6 & 118.3 \\
\hline Upper Bound Estimate & 117.4 & 162.2 \\
\hline
\end{tabular}

However, at the same news conference during which Salazar spoke, Dean Ashe, the Service's Director, said the Service will continue to consider listing as injurious the five other species. Ashe stated that once that process is completed, the Service will publish final determinations on those species. $^{22}$ In its rulemaking, the Service admits that the decision to list only four snakes was done to accommodate the U.S. Office of Management and Budget, and that the nine-snake listing "... is not being rejected and the five other species ... remain under consideration." ${ }^{23}$ So, rather than being a compromise as Secretary Salazar suggests, the decision to list four

20 "Salazar Announces Ban on Importation and Interstate Transportation of Four Giant Snakes that Threaten Everglades.” U.S. Fish and Wildlife Service news release, 17 January 2012.

${ }^{21}$ Fleshler, D. "U.S. Bans Import of Pythons, 3 Other Constrictors." Sun Sentinel, 17 January 2012.

22 "Salazar Announces Ban on Importation and Interstate Transportation of Four Giant Snakes that Threaten Everglades.” U.S. Fish and Wildlife Service news release, 17 January 2012.

23 U.S. Fish and Wildlife Service, 12 January 2012, p. 16.

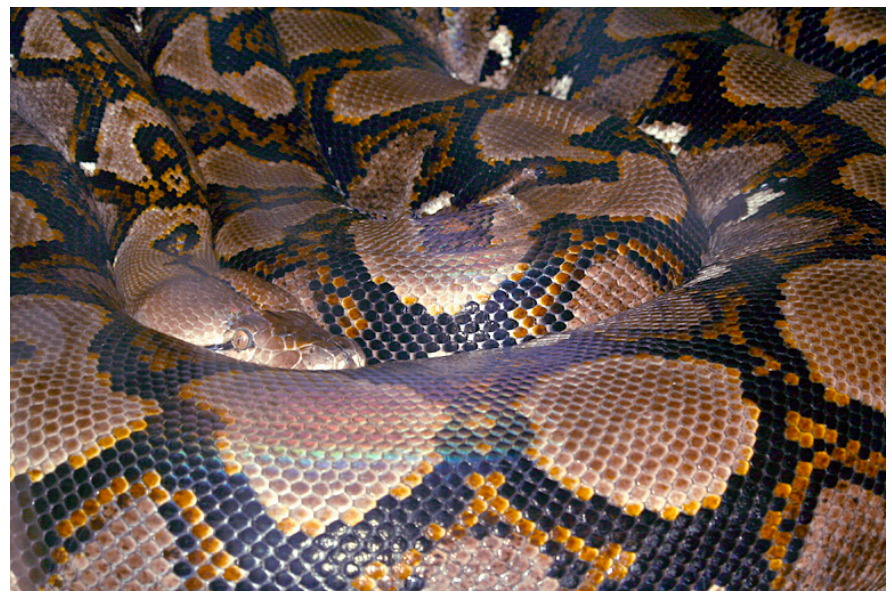

Reticulated Pythons (Python reticulatus) are native to southeastern Asia. They are generally considered to be the world's longest snakes (adults reaching nearly $7 \mathrm{~m}$ in total length, although the average adult size is much less). Photograph by Ruchira Somaweera. 

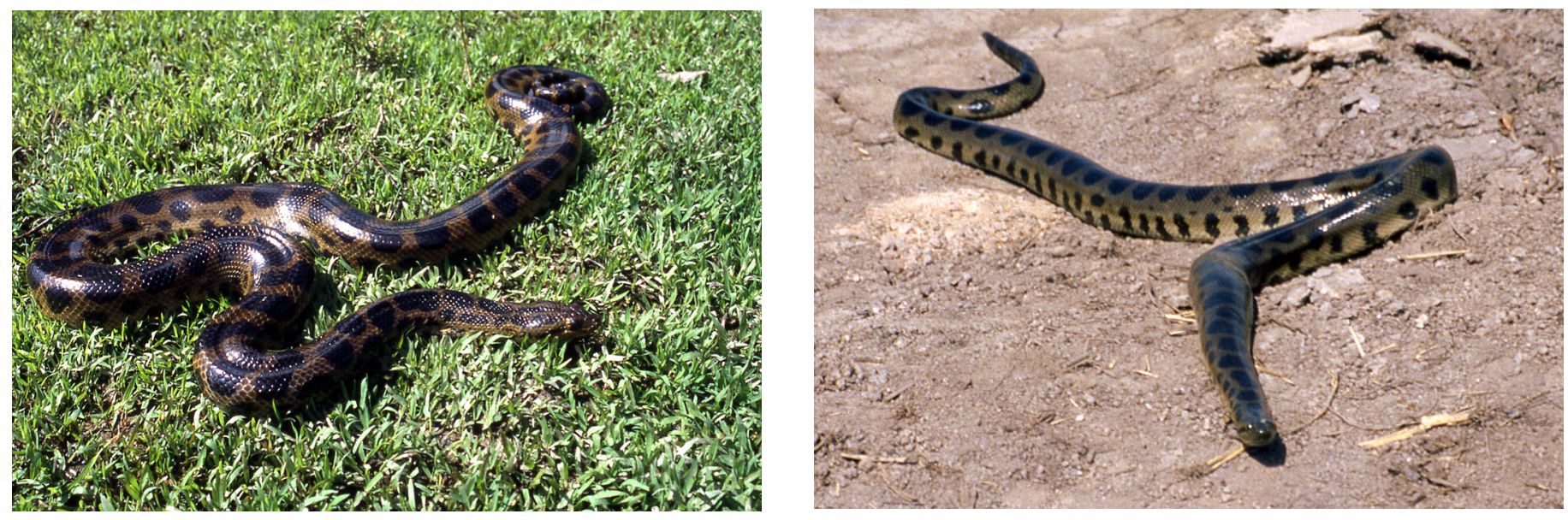

The Dark-spotted or DeSchauensee's Anaconda (Eunectes deschauenseei; left) and the Beni or Bolivian Anaconda (E. beniensis; right). The former has a wide distribution in the Amazon Basin and along coastal areas to the north, whereas the latter has a range restricted to northern Bolivia. Photographs by Lutz Dirksen.

snakes as injurious may be simply the first step in a process to list all nine snakes.

Based on the information we have seen, we estimate that the loss in revenues in the first year after enactment of the rule, assuming a low-impact scenario, is $\$ 8.6-11.7$ million, and assuming a high-impact scenario, is \$15.1-20.7 million. These estimates are slightly lower than those of the Service, which estimates that the four-snake listing will result in an annual reduction of industry revenues of \$3.7-7.6 million and secondary economic costs of \$10.7-21.8 million per year. Our estimates of the ten-year impact of the four-snake listing are shown in Table 3.
A comparison of Tables 2 and 3 shows a large difference in the impacts of a nine-snake listing and a four-snake listing. This difference is due mainly to keeping the Boa Constrictor and, to a lesser extent, Reticulated Python imports and interstate sales legal under a four-snake listing. The difference also represents the benefits to the industry of the compromise. However, to the extent that the Service continues to take the position that the four-snake listing is simply an intermediate step to an eventual nine-snake listing, the estimated costs of the four-snake listing shown in Table 3 are understated and the industry will continue to contract in anticipation of the nine-snake listing. 